\section{Single-Stage Posterolateral Corpectomy and Circumferential Stabilization without Laminectomy in the Upper Thoracic Spine: Cadaveric Study and Report of Three Cases}

\section{Üst Torakal Omurganın Posterior Yaklașım ile Laminektomi Yapılmaksızın Korpektomi Uygulaması ve Tek Seansta Çevresel Stabilizasyonu: Kadavra C̣alıșması ve Üc Olgu Sunumu}

\begin{abstract}
AIM: Surgical approach to the upper thoracic spine diseases is challenging since anterior interventions to this region are quite complicated with the presence of major vascular elements or important visceral and soft-tissue structures.

MATERIAL and METHODS: Operative technique was performed initially on eight cadavers and then on three consecutive patients. Costotransvesectomy was performed on the left side and pediculectomy were added on the contralateral side to achieve wide visual angle during corpectomy. A cage was implanted into the field of corpectomy from the left side and the stabilization procedure was completed with posterior instrumentation.
\end{abstract}

RESULTS: Anterior low cervical approach is less invasive than posterior approach for T2 level and above.The area below T3 level includes the heart, aorta, common carotid or brachiocephalic artery and thoracic duct favoring the safety of posterior approach which provides a sufficient surgical window for corpectomy and circumferential stabilization at a single operation.

CONCLUSION: The corpectomy procedure could be clearly performed under bilateral visualization of healthy bony margins with this technique. Although preserved laminae and spinous process lose the connection to the involved segment and hanged to adjacent levels only with posterior ligamentous complex, we propose that a chance of interlaminar fusion could further contribute to spinal stabilization rather than posterior instrumentation only.

KEYWORDS: Upper thoracic spine, Corpectomy, Laminectomy, Posterior approach, Single stage, Circumferential stabilization

\section{Öz}

AMAÇ: Üst torakal omurgaya anterior yaklaşım büyük damarsal yapılar ve önemli yumuşak doku içeriği nedeniyle tartışmalıdır.

YÖNTEM ve GEREÇ: Bu çalışmada, tanımlanan teknik önce 8 kadavra üzerinde ve ardından 3 olguya uygulanmıştır. Bunun için soldan kostotransversektomi ve karşı taraftan pedikülektomi yapılarak korpektomi koridoru oluşturulmuştur. Korpektomi alanına soldan kafes yerleştirilerek peşinden posteriyor vida-rod sistemi ile stabilizasyon tamamlanmıştır.

BULGULAR: Torakal 2 ve üzerinde anterior alt servikal yaklaşım daha az invaziv ve yeterlidir. Torakal 3 ve altında ise kalp, aort, ductus thoracicus, karotis ve brakiyosefalik arterler nedeniyle posteriyor yaklaşım çevresel stabilizasyon için güvenli ve yeterli imkanı sağlamaktadır.

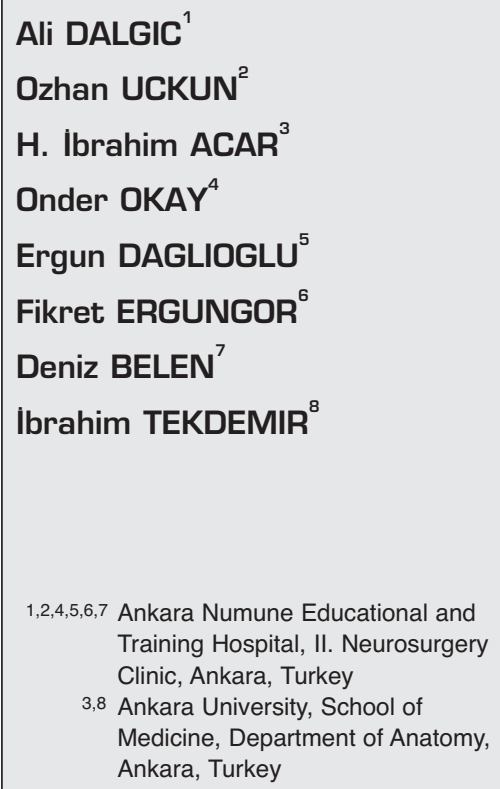
Medicine, Department of Anatomy, Ankara, Turkey

Received : 17.08.2009

Accepted : 04.12.2009

This paper was presented as oral presentation in 9th $^{\text {th }}$ Black Sea Congress (October 2009, Istanbul/TURKEY)

Correspondence address:

Ali DALGIC

E-mail: alidalgic@yahoo.com 
SONUÇ: Bu teknik ile korpektomi sınırları iki taraflı olarak sağlıklı kemik yapıdan ayrımı yapılarak uygulanabilir. Korunmuş olan lamina ve spinöz proçesler korpus bağlantısını kaybetmesine rağmen posteriyor ligamentöz kompleks aracılığı ile komşu segmentler ile bağlantısını sürdürmekte olup böylece interlaminer bölgede kemik füzyon alanı sağlanabilmetedir. Bu füzyon omurga stabilizasyonuna yalnızca enstürümantasyon sisteminden daha fazla katkıda bulunacaktır.

ANAHTAR SÖZCÜKLER: Üst torakal omurga, Korpektomi, Laminektomi, Posteriyor yaklaşım, Tek seans, Çevresel stabilizasyon

\section{INTRODUCTION}

The upper thoracic spine is a transitional area from a mobile, lordotic cervical spine to a rigid, kyphotic thoracic spine therefore the region is challenging for spinal surgeons. Trauma, infections, tumors or other pathological processes may change the biomechanical function of the upper thoracic spine and result in instability. Surgery for upper thoracic region may be complicated with the presence of important visceral and soft-tissue structures $(10,16,17,20,28)$.

In general, the goal of the surgery is to decompress the thoracic spinal cord and provide immediate stabilization. Because of the individual anatomical and biomechanical characteristics of the upper thoracic spine, a safe approach to this region is still controversial. The anterior approaches have been listed as low cervical, supraclavicular, transthoracic, transaxillary, combined cervicothoracic, sternal splitting or modified sternal approaches $(5,16,19,26,30)$. Anterior approach to the upper thoracic spine is difficult since there are bony obstructions such as the manubrium, clavicle, ribs and the deep location of vertebral bodies due to thoracic kyphosis. The area also includes vital structures such as the major blood vessels, recurrent laryngeal nerve, thoracic duct, and sympathetic ganglions as well as the lung and heart $(16,17,30)$.

Conventional midline posterior approach is usually preferred to achieve posterior decompression of spinal cord and spinal stabilization. However, this approach provides limited exposure when the lesion is located at the anterior column $(27,30)$. Standard thoracotomy that enters the chest through the bed of the third rib may also provide a sufficient surgical exposure for upper thoracic area however the scapula and remaining ribs restrict an adequate exposure $(3,30)$. Combined approaches provide access to anterior and posterior elements (39) but they are associated with severe intraoperative complications and have the potential to cause or exacerbate preexisting comorbidities, principally of the respiratory system (35).

Costotransversectomy provides access to the posterolateral vertebral body and lateral portion of the spinal canal (27). If the procedure is performed bilaterally it provides anterior decompression, fusion and posterior stabilization. In this clinicoanatomical study, thoracic corpectomy via left costotransversectomy was performed on 8 cadavers and pediculectomy was also added on the contralateral side without damaging laminae, spinous process and posterior ligamentous complex (PLC: ligamentum flavum, interspinous and supraspinous ligaments). Furthermore, surgical and radiological details of three cases operated with the same approach due to vertebral body pathologies were discussed.

\section{MATERIAL and METHODS}

The study involves two sections: In the first part of the study, eight cadavers were subjected to left costotransversectomy and contralateral pediculectomy without laminectomy to achieve corpectomy and posterior stabilization at upper thoracic spine. In the second part of the study, three patients were operated with the same approach for vertebral body involvement at upper thoracic region (Table I).

\section{Cadaveric Study}

Eight formalin-fixed cadavers of the cervicothoracic spine were obtained for this study. The cadavers were divided into four groups according to operational segments: three cadavers for T2 level, two cadavers for T3 level, two cadavers for T4 level and one cadaver for T3-T4 (two levels) corpectomy.

Cervicothoracic spine was exposed bilaterally in all cadavers. All the cadaveric procedures were performed with the aid of $2.5 \mathrm{X}$ surgical loupe 
Table I: Demographic and Clinical Characteristics of Three Patients Operated with Unilateral Costotransversectomy and Contralateral Pediculectomy ( ${ }^{*}$ Frankel Grading: A: Complete Motor and Sensory Paralysis Below Lesion, B: Complete Motor Paralysis, but Some Residual Sensory Perception Below Lesion, C: Residual Motor Function but of No Practical Use, D: Useful but Subnormal Motor Function Below Lesion, E: Normal) Abbreviation: M: Male

\begin{tabular}{|c|c|c|c|c|c|c|c|c|}
\hline & Age & Sex & Level & $\begin{array}{c}\text { Frankel } \\
\text { Grade* }^{*}\end{array}$ & Diagnosis & $\begin{array}{c}\text { Neurological } \\
\text { Improvement }\end{array}$ & Fusion & $\begin{array}{c}\text { Follow-up } \\
\text { (month) }\end{array}$ \\
\hline Case 1 & 36 & $\mathrm{M}$ & $\mathrm{T} 4$ & $\mathrm{~A}$ & Trauma & No & Yes & 21 \\
\hline Case 2 & 27 & $\mathrm{M}$ & T4 and T5 & $\mathrm{E}$ & Tuberculosis & Yes & Yes & 16 \\
\hline Case 3 & 57 & $\mathrm{M}$ & $\mathrm{T} 4$ & $\mathrm{C}$ & Tumor & Yes & No & 10 \\
\hline
\end{tabular}

(Oculus binocular surgical loupe, Western Ophthalmics Incorporation, Germany). Facet joint, transverse process, pedicle, one fourth of the lamina adjacent to the facet joint ( $x$ distance, Figure $1 \mathrm{~A}, \mathrm{~B}$ ) and first two centimeters of the proximal rib ( $y$ distance, Figure $1 \mathrm{~A}, \mathrm{~B}$ ) were completely removed on the left with great care not to induce any pleural injury (Figure 1A,B). Corpectomy and discectomy for superior and inferior adjacent levels were performed avoiding injury to the lamina, spinous process and PLC. The vertebral body was drilled to the boundaries of periosteum, ensuring the safety of the mediastinum and dural sac. After meticulous dissection of periosteum from adjacent mediastinum, vertebral body, disc and endplates in both the cranial and caudal adjacent segments had been curetted. However, about one fourth of corpectomy could not be completed unilaterally due to obstruction of visual angle by the scapula (area $\mathrm{z}$, Figure 2A,B). Facetectomy and pediculectomy were added on the contralateral side because contralateral periosteal border was not sufficiently exposed to operate on opposite edge of corpectomy (Figure 2A,B).

The lower nerve root was sacrificed on the left side and a mesh cage was inserted from the same side to the field of corpectomy. Insertion of transpedicular screws bilaterally into adjacent superior and inferior vertebrae facilitates forced distraction during cage implantation. After the preservation of vertebral alignment on anterior column, posterior stabilization was extended to one upper and lower segment.

In cadavers subjected to $\mathrm{T} 2$ corpectomy without laminectomy (three cadavers), instrumentation was extended to the superior direction with bilateral $\mathrm{C} 5$, C6 lateral mass and C7, T1 pedicle screws and to inferior direction with bilateral T3, T4, T5 hooks which were then fixed with rods and transverse bars. In cadavers subjected to T3 (two cadavers) or T4 (two cadavers) corpectomy, same procedure was performed and adjacent two segments were stabilized superior and inferiorly with transpedicular screws and rods. Only in one cadaver $\mathrm{T} 4$ and T5 corpectomies were performed with the removal of T4, T5 transverse processes, facet joints, pedicles and proximal $2 \mathrm{~cm}$ of left T4 rib only. Removal of left T5 rib is thought to be unnecessary since removal of a single rib is quite enough for

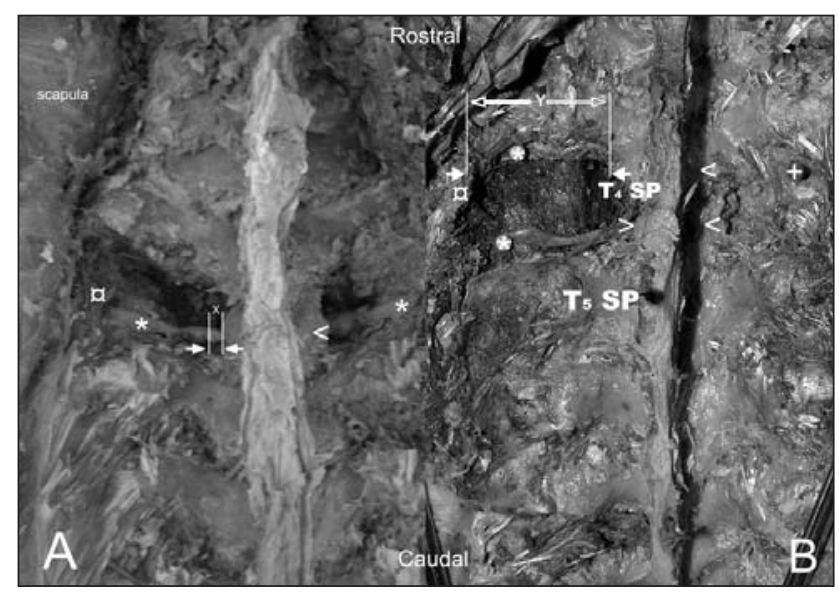

Figure 1: A. Photograph of cadaveric study just before implantation of posterior stabilization system. Note spinous process of thoracic vertebra 3 (T3SP) after T3 corpectomy. $x$ denotes to the limited portion of laminectomy (one quarter of lamina), B. Photograph of another cadaver after two level corpectomies. T4SP denotes to T4 and T5SP denotes to T5 vertebra. Removal of fourth rib on the left provided a wide exposure for T4 and T5 corpectomies. $y$ shows the distance after removal of proximal 2 centimeters of the rib

Abbreviations: SP: Processus Spinosus, $>$ : preserved laminae on the left, <: preserved laminae on the right, *: nerve roots, ?: removed ribs, + : intact rib, $x$ : limited portion of laminectomy (about one quarter of lamina), $y$ : removed segment of the rib (proximal 2 centimeters) 


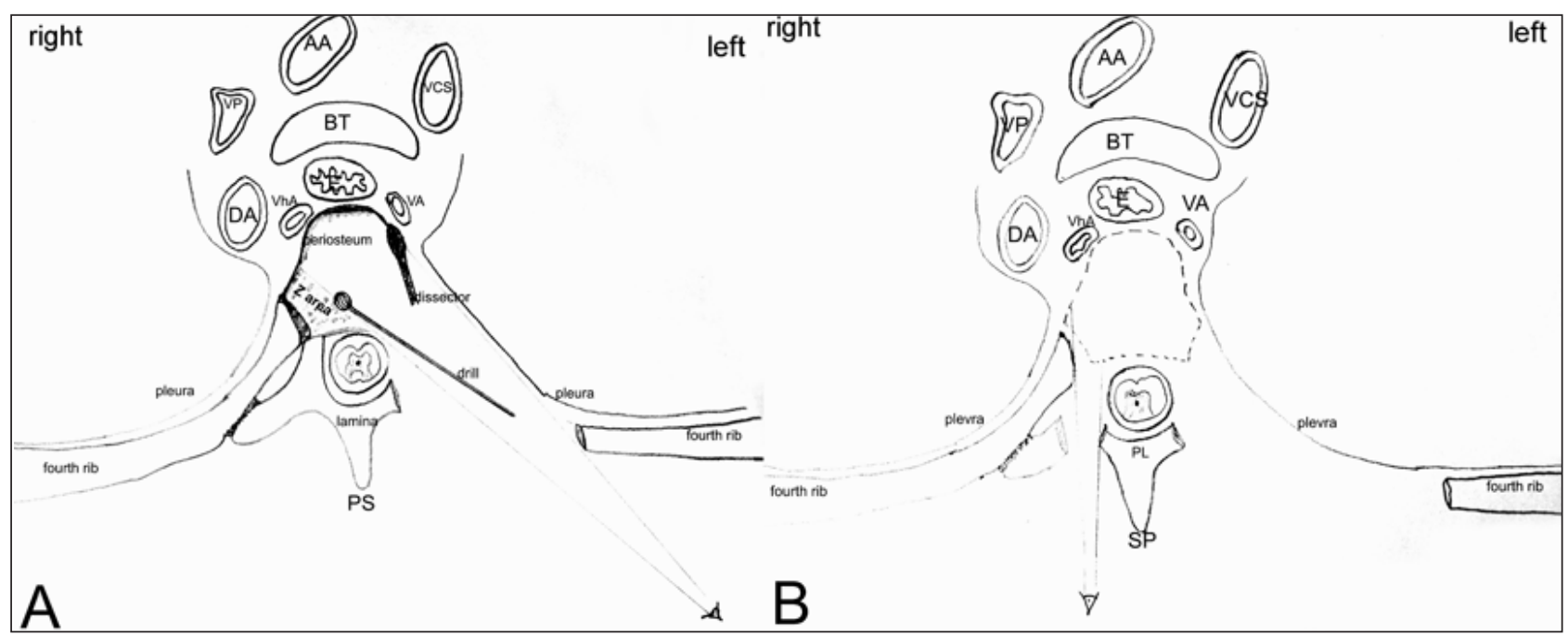

Figure 2: A. Artist's illustration demonstrating visual angle provided with the removal of suggested vertebral segments. Remnant edge of the vertebral body under the tip of drill could not be removed under direct vision surgically. $z$ denotes to the remaining area after corpectomy, B. Removal of the remnant part shown in Figure $1 \mathrm{~A}$ is removed after contralateral pediculectomy while preserving lamina and related posterior elements.

Abbreviations: AA: Ascending aorta, DA: Descending aorta, VP: Vena pulmonales, VCS: Vena cava superior, VA: Vena azygos, VhA: Vena hemiazygos, BT: Bifurcation of trachea, PS: Processus Spinosus, z: remaining area after corpectomy

exposure during corpectomy and cage insertion (Figure 3A,B).

Pleura, mediastinum and/or dura were not opened in any of the cadavers. One level as well as two level corpectomies may be performed to decompress spinal cord while achieving circumferential stabilization of upper thoracic spine at a single stage.

\section{Report of Three Cases}

Case 1: A 36-year-old man was admitted to the emergency department with the diagnosis of spinal trauma. On neurological examination, the patient was paraplegic and had anesthesia under T5 level. Radiological studies revealed a fracture dislocation and collapsed T4 vertebra (Figure 4A,B,C) and stabilization was planned from posterior approach. The patient was placed in prone position with the left side higher than the right side. " $\mathrm{T}$ " shaped incision was used and the paravertebral muscles were bluntly dissected. On the left side, vertebral body was observed after the removal of the fourth rib (proximal $2 \mathrm{~cm}$ ) and transverse process. Since corpectomy could not be completed from the left side despite T5 root sacrifice, pediculectomy and facetectomy without laminectomy were also performed on the contralateral side to complete corpectomy within safe margins of the periosteum.

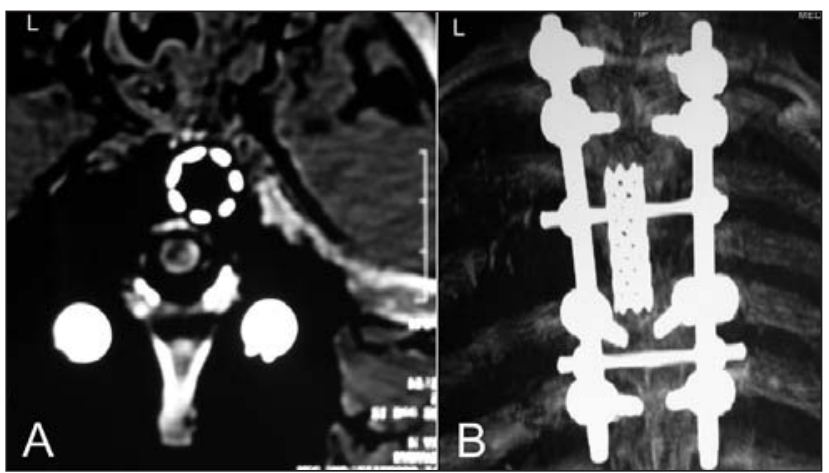

Figure 3: Axial $(A)$ and tri-dimensional reconstruction $C T$ (B) of cadavers from the study after implantation of posterior stabilization system. Note the inserted mesh cage in both cadavers.

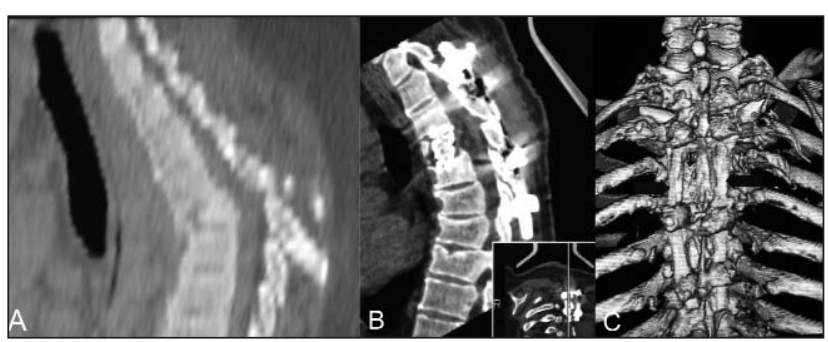

Figure 4: Sagittal CT reconstruction of Case 1 before $(A)$ and after $(\boldsymbol{B})$ surgical procedures. Note the correction of thoracal kyphotic angulation in B. Postoperative tri-dimensional CT reconstruction $(C)$ demonstrates interlaminar fusion (short arrows) and stabilizing rods (long arrows). 
Adjacent T3-4 and T4-5 discectomies were also performed to achieve cage implantation and interbody fusion.

After the implantation of bilateral pedicle screws to $\mathrm{T} 3$ and $\mathrm{T} 5$ vertebrae, a mesh cage was placed through costotransversectomy area. The adjacent vertebral bodies were distracted to place the mesh cage. Posterior stabilization was further completed with the involvement of bilateral T2 and T6 segments with laminar hooks. All of the exposed vertebral laminas were decorticated and bone chips were used for bony fusion. There was no operative complication and neurological deterioration. The patient was advised to use thoracolumbar brace for three months. Both interbody and interlaminar fusion was noticed at the end of 14 months of followup (Figure $4 \mathrm{~A}, \mathrm{~B}, \mathrm{C})$.

Case 2: A 27-year-old man was referred to our hospital with complaints of paraparesis and back pain. Sagittal MRI revealed loss of height on fourth and fifth thoracic vertebrae with T4-T5 discitis and kyphotic deformity of the thoracic spine. Axial T1weighted MRI showed marked compression of thoracic spinal cord (Figure 5A,B,C,D,E). T4 and T5 corpectomies were performed via $\mathrm{T} 4$ costotransversectomy and T5 pediculectomy on the left and T4, T5 pediculectomy on the contralateral site. Posterior transpedicular screws were inserted to one level above and below corpectomies (Bilateral T3 and T6 pedicles). This was followed by the insertion of an expandable cage while avoiding forced distraction as reported in Case 1. Stabilization was completed with further placement of laminar hooks above (Bilateral T2 laminas) and transpedicular screws below (Bilateral T7 pedicles) as well as fixation of rods. There were no peroperative complications. The patient's condition improved a week after the operation and started to walk afterwards. Histopathological specimens were revealed as granulomatous infection and caseification necrosis. Combined antibiotic regimen was started for vertebral tuberculous abscess protocol that consists of isoniazid $5 \mathrm{mg} / \mathrm{kg} / \mathrm{d}$, rifampicin $10 \mathrm{mg} / \mathrm{kg} / \mathrm{d}$, ethambutol $15 \mathrm{mg} / \mathrm{kg} / \mathrm{d}$ and pyrazinamide 35 $\mathrm{mg} / \mathrm{kg} / \mathrm{d}$ for three months. This combination was then restricted to triple regimen with the removal of pyrazinamid for another three months. The regimen was switched to dual therapy of isoniazid and rifampicin for another 6 months. Neurological findings were normal at the eighth month of followup with bony fusion and no kyphotic angulation on tri-dimensional CT scans (Figure 5A,B,C,D,E).

Case 3: 57-year-old man was referred to our center with inability to walk and marked paraparesis. Clinical history was unremarkable. Sagittal T1-weighted MRI revealed collapse of T4

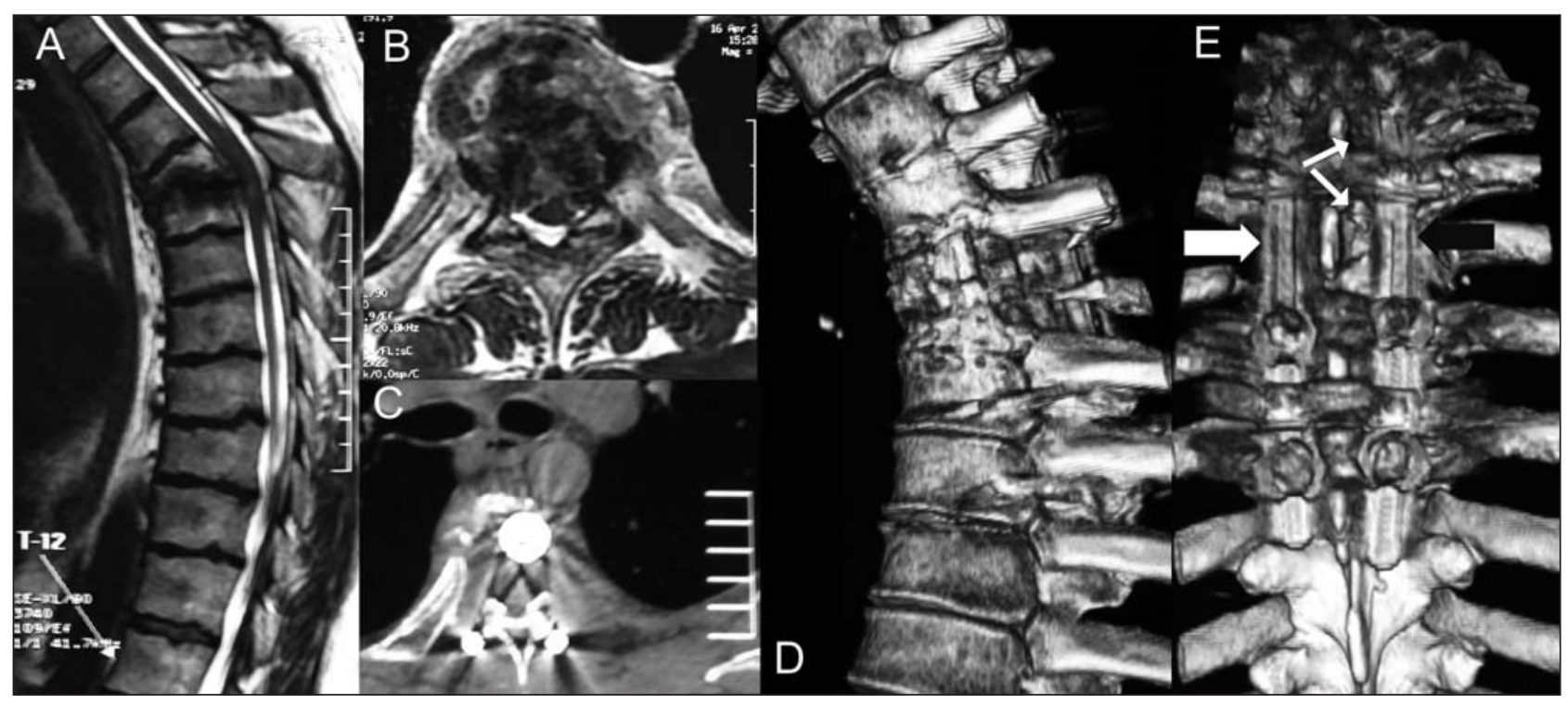

Figure 5: A. Sagittal T2-weighted thoracic MRI before the operation shows loss of vertebral height and disc space on T4 and T5 vertebrae. B. Axial T1-weighted MR image with contrast shows epidural compression due to vertebral body involvement. C. Postoperative contrast enhanced axial CT image of the operative field after decompression and posterior stabilization. Lateral D. and posterior E. view on tri-dimensional CT reconstructions of the operative field shows both interbody and interlaminar bony fusion. 
vertebral body without involvement of adjacent disc spaces. Axial T1-weighted gadolinium enhanced MR image showed severe mass effect on thoracic spinal cord (Figure 6A,B,C,D,E,F). The patient was urgently operated to decompress the spinal cord and provide circumferential stabilization. T4 corpectomy was performed with costotransversectomy on the left and pediculectomy on the right. Transpedicular screws were inserted to upper and lower two vertebrae before the implantation of an expandable cage. Circumferential stabilization was completed with the fixation of rods. Histopathological specimens were compatible with metastatic adenocarcinoma. The patient started to walk the day after the operation and there was no recurrence on MRI scans at the fourth month of follow-up, however there was marked residual kyphotic deformity (Figure 6A,B,C,D,E,F).

\section{DISCUSSION}

Best surgical intervention to vertebral body lesions of upper thoracic spine is still a matter of debate. There is a growing tendency for posterior approaches to upper thoracic region and various techniques were defined in the literature $(1,4,8,16$,
$21,25,33,35,36,39)$. We suggest that if there is no laminar involvement, corpectomy may be performed via costotransversectomy on one side and pediculectomy on the contralateral side in wellselected cases although it is not a unique technique. The main aim of this study is to preserve the lamina and the PLC which provides additional fusion area and biomechanically increased stabilization rate. This procedure is safe, effective and contributes to spinal stability since there is no need to remove lamina, spinous process and PLC. Circumferential instrumentation including posterior transpedicular screw-hook-rod system and cage implantation at a single operation further support thoracic alignment, stabilization, interbody as well as interlaminar fusion.

In general, operative approach to involved vertebra is primarily determined by the form, location, and / or type of the lesion. However, this is not true for upper thoracic spine due to neighboring anatomical structures and biomechanical characteristics. Several surgical approaches were defined for this region that can be categorized mainly into four groups: posterior, posterolateral, anterior, and anterolateral approaches $(16,20)$.

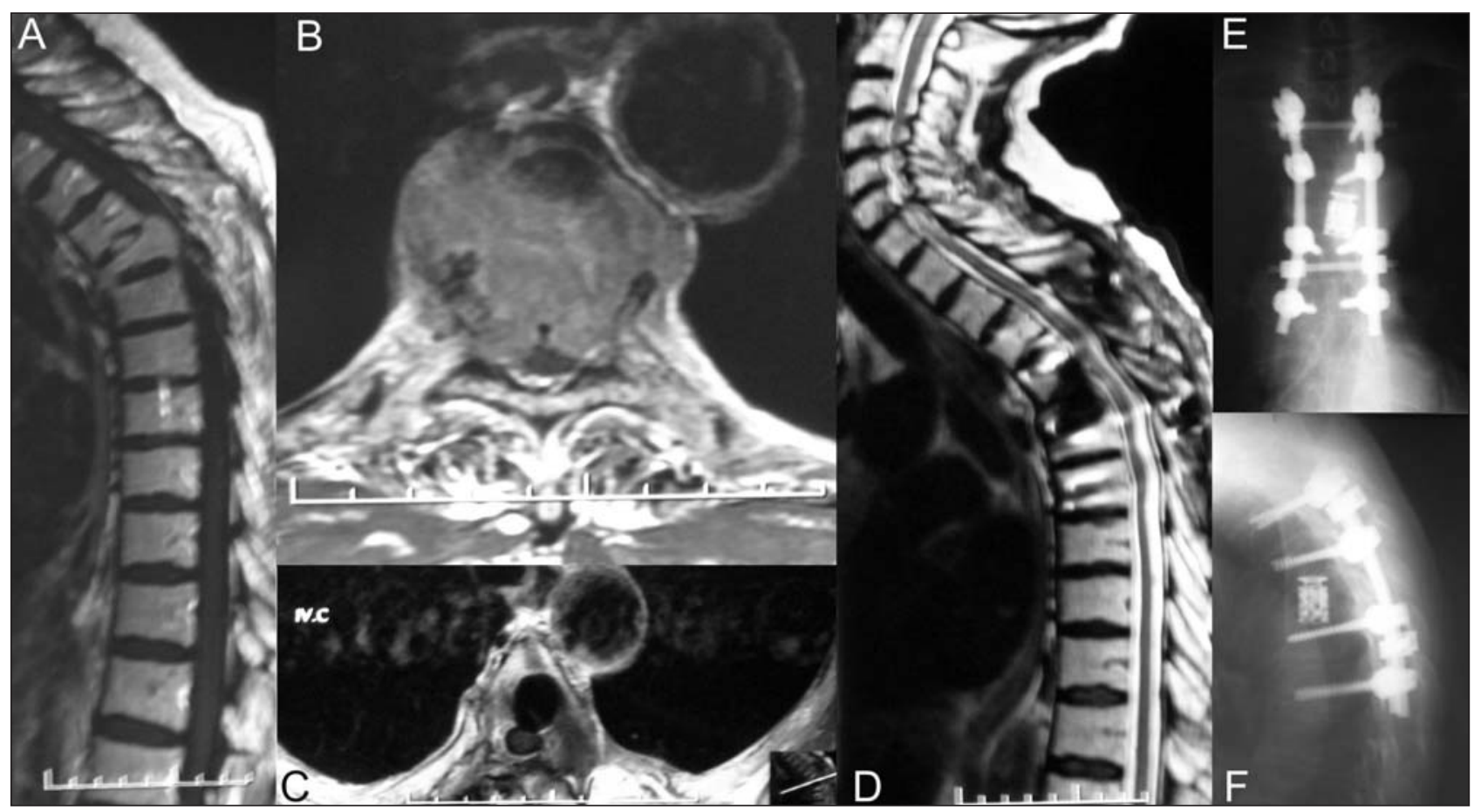

Figure 6: Marked loss of height on gadolinium enhanced sagittal (A) T1-weighted image of thoracic vertebrae. Axial T1-weighted section (B) with gadolinium demonstrates marked epidural mass effect on thoracic spinal cord. Postoperative axial T1-weighted MR image $(C)$ of the same section shows significant decompression of thoracic spinal cord. Postoperative sagittal T2-weighted image (D) shows marked correction of preoperative kyphosis. Anteroposterior (E) and lateral (F)X-rays show corrected thoracic alignment with the inserted posterior metallic construct and distractable cage. 


\section{Anterior and Combined Approaches to Upper Thoracic Spine}

Anterior cervical approach can provide decompression and stabilization up to T1 level. Low cervical approach is an extension of the anterior approach to the manubrium of sternum splitting of which provides exposure of T2 level (14, 16, 17, 28). In the study of cervicothoracic junction lesions (CTJ) by $\mathrm{An}$ et al, anterior low cervical approach was described among 7 cases with lesions of T2 or higher (2). Boockvar et al. also used the same technique for 10 cases with radiculopathy or myelopathy due to cervical spondylosis at T1 level or higher (6). These two studies include a purely supramanubrial dissection that is extended to the limit of the thoracic inlet. According to Kaya et al, T1 and T2 vertebral body resection can be achieved through a simple supramanubrial dissection of cervicothoracic and upper thoracic lesions (16). We suggest anterior low cervical approach for T2 corpectomy which is less invasive than the posterior approach and it does not require extensive dissection of the posterior paravertebral muscles as reported by Kaya et al. (16). Nevertheless, this approach could not provide the exposure of $\mathrm{T} 3$ and lower segments, and can be particularly difficult in patients with short neck and high shoulder level. Besides individual variations, there are general anatomical factors like the shape of the thoracic aperture, the location of the manubrium and the degree of cervicothoracic kyphosis which definitely limit the surgical exposure $(16,30,38)$.

Anterior low cervical approach can be extended downwards with the resection of clavicle, sternotomy or combined thoracotomy to provide a wider surgical field $(17,37)$. Although sternal resection, either partially (the manubrium alone) or completely split (sternotomy), allows decompression of the spinal cord up to T3 level, anterior instrumentation below T4 will not be possible through sternum resection $(10,16)$. Because anterior approaches are limited with the proximity of the great vessels like the aorta inferiorly, common carotid or brachiocephalic artery superiorly and lower brachial plexus, complete split of the sternum does not add a further caudal exposure compared with a partial resection (the manubrium alone) $(3,13$, $16,38)$. Other disadvantages are the ligation and section of innominate vein or injury of thoracic duct which are all situated at the level of $\mathrm{T} 4$ or $\mathrm{T} 5(17,37)$.
Sternotomy can also be associated with significant morbidity (10) as well as rib fractures, lung contusion or hemothorax which all lengthen the postoperative stay particularly in patients with trauma as reported in Case 1.

Combined approaches may provide access to anterior and posterior elements of the whole spinal column and circumferential stabilization $(2,15,39)$ however surgical manipulations are limited as described above (16). However, combined approaches are usually associated with prolonged operative time, increased blood loss and wound infection rate and also the potential to cause, or exacerbate preexisting co-morbidities, principally of the respiratory system $(13,35)$.

\section{Posterior and Posterolateral Approaches to Upper Thoracic Spine}

Anterior approach is traditionally preferred for lesions of the anterior column while posterior approach is reserved for lesions with bilateral pedicle or extensive posterior element involvement $(1,4,8,20,21,23,32,36)$. Posterior approach allows excellent decompression, with early visualization of the lesion and neural structures. Posterior approaches with laminectomy may be used for decompression of a lesion causing extensive destruction of the posterior spinal elements but it does not provide adequate exposure of the anterior spinal elements $(2,16,30)$. Lateral extracavitary approach can be considered as a relatively safe and less extensive approach than traditional thoracotomy but exposure is limited by the shoulder, scapula and the reversal of thoracic kyphosis which further complicates the access to vertebral bodies (3, $13,16,23,31,35)$. Although there is a debate about the extent of decompression, a trend towards posterior approaches were increasing in the last decade. Costotransversectomy allows a wider exposure of the involved vertebra with an improved angle of circumferential decompression (27). Adequate and safe decompression of the spinal cord and immediately obtained circumferential stabilization were reported as the most important advantages of posterior approaches $(1,4,8,16,21,22$, $25,32,35,36)$. Also, Fessler et al. emphasized the importance of costotransversectomy with a lateral parascapular extrapleural approach which is again favorable for corpectomy and instrumentation for upper thoracic spine (11). Furthermore, Snell et al. 
described a similar technique in the lower thoracic spine with bilateral costotransversectomy (33). The approach described here showed similarity with the technique described by Fessler and Snell et al. and provided almost identical exposure for corpectomy and stabilization $(11,33)$. We propose partial removal of a single rib (proximal $2 \mathrm{~cm}$ only) is sufficient for corpectomy and implantation of the cage although Fessler et al. removed two ribs with an indefinite lateral extension. Moreover, borders of corpectomy and healthy bony tissue were better visualized bilaterally with the unilateral corpectomy and contralateral pediculectomy, in particular infectious and tumoral involvements. Contralateral pediculectomy provides a safer surgical removal of the contralateral edge of corpus while providing a more confirmed visualization of periosteal as well as diseased bony margins. A more sufficient and safe angle for corpectomy and cage implantation is provided while avoiding blind resection of the vertebral body edge (Figure 2A,B). Although preservation of lamina, spinous process and PLC was thought to be unnecessary with the removal bilateral pedicles, overt interlaminar fusion in Case 1 and 2 contributes to the stability spinal column.

\section{Biomechanical Considerations}

There are few biomechanical studies to address the importance of stabilization on CTJ or upper thoracic spine despite the predominance of clinical studies at this region $(18,29,34)$. Pyrbis et al. reported posterior instrumentation to be most appropriate for stabilization of a 2-column injury. Anterior and posterior reconstruction should be made after a corpectomy since the corpectomy model demonstrated similar flexible properties in a 3-column injury model (29). Kreshak et al. pointed out that posterior instrumentation adequately stabilized a posterior 2-column injury but inappropriate for a 3-column injury, particularly in extension (18). On the other hand, Bueff et al. reported that anterior plates provided a less rigid construct than posterior ones (7). Based on the data above, destabilized spine must be constructed by circumferential instrumentation.

In the literature, the laminae were removed to achieve decompression and/or provide wide exposure of the operative field particularly in primary bone tumors or metastasis with lamina involvement or epidural mass effect $(1,4,8,20,25$,
32, 35, 36, 39). Nevertheless, initial attempts of laminectomy for spinal decompression or resection of the posterior elements without instrumentation often leads to progressive kyphosis and increased neurological deficits (4). Steinmets et al. emphasized the benefit of posterior instrumentation for upper thoracic region since laminectomy alone was statistically associated with fusion failure (34).

The tensile strength of ligamentum flavum is meanly 300 newtons at thoracic levels and interspinous ligaments can stand to a tension of 20150 newtons (24). Thus preservation of PLC may assist spinal stability and posterior elements can be beneficial in cases with intact posterior column since anterior colon is already involved with the lesion. In addition, decortication of the preserved lamina may increase the chance of posterior interlaminar bony fusion which was marked in the first two cases (Case 1 and 2). Although preserved laminae can be regarded as free-floating with intact PLC and further interlaminar fusion, we suppose that their contribution to spinal stabilization should not be underestimated. Chen et al. emphasized the importance of posterior elements in the instrumented spine and reported that instability developed less likely (9). Another biomechanical study by Gillespie et al. demonstrated the contribution of supraspinous and interspinous ligaments to the applied flexion moments of the spine and aided in spinal integrity (12). The limitations of the studies above include inability to measure the isolated strength of the related colon whether it is anterior, posterior or middle. Further studies should be planned to measure the exact contribution of each colon to the stability.

\section{Technical Standpoints}

In this clinicoanatomical study, we intend to achieve decompression and stabilization at the same operation within the defined anatomical corridors. Bilateral approach with left costotransversectomy and contralateral pediculectomy counteracts the lateral visual compromise by scapula and provides adequate working space for corpectomy. This approach also provides interbody fusion with cage and enough space for bony fusion on posterior column with the preservation of posterior elements. Although laminectomy provides early visualization of dural sac, preservation of bony elements and PLC is reasonable particularly in cases with a long 
expectation of overall survival. Another point is the removal of a single rib with a limited proximal resection ( $2 \mathrm{~cm}$ only) even in cases necessitating two level corpectomies. The main limitation of this study is the removal of contralateral pedicle in addition to corpectomy and costotransversectomy. This resection results in the loss of connection to the involved segment and hanged to adjacent levels only with PLC. However, preserved PLC aided in spinal stability and following interlaminar fusion further contributes to the stability $(9,12)$.

Upper thoracic spine is a neighboring zone to CTJ which acts as a transitional zone from a mobile and lordotic cervical segment to an immobile and kyphotic thoracic vertebra. Because of this angulation's on upper thoracic area, particularly T1, T2 and T3 levels, transpedicular screws should be inserted with the guidance of fluoroscopy. On the other hand, pedicles of these segments are thin and manipulations during tapping or drilling of pedicle could be challenging. Laminar hooks may be a better alternative in case of pedicle injury. Hook system is safe, stable and allows an effective stabilization in thoracic spine than cervical and lumbar segments.

A mesh cage was inserted into the region of corpectomy during cadaveric procedures and the first patient of our series. However, forced distraction was required for cage insertion. To avoid distractive injury, we used expandable cage in the last two cases to maintain thoracic alignment. Use of an expandable cage is feasible and appropriate for posterior insertion thus eliminating the need for a second stage anterior approach through a single incision $(32,33)$. Moreover, posterior pedicle screw or hook fixation at the same operation supports anterior column with the formation of posterior tension band and alignment.

\section{CONCLUSION}

We propose low anterior cervical approach and submanubrial dissection for lesions of $\mathrm{T} 1$ and $\mathrm{T} 2$ which is less invasive than posterior approach. The technique defined in the present report is safer and more appropriate for cases with isolated anterior and/or middle column involvement $\mathrm{T} 3$ and below levels. This technique, although it is not completely novel, provides a better surgical corridor for corpectomy and circumferential stabilization at a single stage with the preservation of lamina, spinous process and PLC as an adjunct to stability and interlaminar fusion. Well-selected cases having traumatic, infectious or tumoral lesions without the involvement of posterior column could be managed with this technique under direct visualization of healthy bony margins. Although laminae and spinous process lose the connection to the involved segment and hanged to adjacent levels only with PLC, we propose that a chance of interlaminar fusion could further contribute to spinal stabilization rather than instrumentation only.

\section{REFERENCES}

1. Akeyson EW, Mccutcheon IE: Single-stage posterior vertebrectomy and replacement combined with posterior instrumentation for spinal metastasis. J Neurosurg 85: 211 220, 1996

2. An HS, Vaccaro A, Cotler JM, Lin S: Spinal disorders at the cervicothoracic junction. Spine 19: 2557 - 2564, 1994

3. Anderson TM, Mansour KA, Miller Jr JI: Thoracic approaches to anterior spinal operations: anterior thoracic approaches. Ann Thorac Surg 55: 1447 - 1451, 1993

4. Bilsky MH, Boland P, Lis E, Raizer JJ, Healey JH: Single-stage posterolateral transpedicle approach for spondylectomy, epidural decompression, and circumferential fusion of spinal metastases. Spine 25: 2240 - 2250, 2000

5. Birch R, Bonney G, Marshall RW: A surgical approach to the cervicothoracic spine. J Bone Joint Surg [Br] 72 :904-907, 1990

6. Boockvar JA, Philips MF, Telfeian AE, O'Rourke DM, Marcotte PJ: Results and risk factors for anterior cervicothoracic junction surgery. J Neurosurg (Spine) 94: 12 - 17, 2001

7. Bueff HU, Lotz JC, Colliou OK, Khapchik V, Ashford F, Hu SS, Bozic K, Bradford DS: Instrumentation of the cervicothoracic junction after destabilization. Spine 20: 1789 - 1792, 1995

8. Cahill DW, Kumar R: Palliative subtotal vertebrectomy with anterior and posterior reconstruction via a single posterior approach. J Neurosurg (Spine) 90: 42 - 47, 1999

9. Chen LH, Lai PL, Tai CL, Niu CC, Fu TS, Chen WJ: The effect of interspinous ligament integrity on adjacent segment instability after lumbar instrumentation and laminectomy--an experimental study in porcine model. Biomed Mater Eng16: $261-267,2006$

10. Comey CH, McLaughlin MR, Moossy J: Anterior thoracic corpectomy without sternotomy: A strategy for malignant disease of the upper thoracic spine. Acta Neurochir (Wien) 139: $712-718,1997$

11. Fessler RG, Dietze DD Jr, Millan MM, Peace D: Lateral parascapular extrapleural approach to the upper thoracic spine. J Neurosurg; 75: 349 - 355, 1991

12. Gillespie KA, Dickey JP: Biomechanical role of lumbar spine ligaments in flexion and extension: determination using a parallel linkage robot and a porcine model. Spine 29: 1208 1216, 2004

13. Gokaslan ZL, York JE, Walsh GL McCutcheon IE, Lang FF, Putnam JB Jr, Wildrick DM, Swisher SG, Abi-Said D, Sawaya R: Transthoracic vertebrectomy for metastatic spinal tumors. J Neurosurg 89: 599 - 609, 1998 
14. Hartl R, Theodore N, Dickman CA: Anterior approaches for the management of thoracic spine fractures. Oper Tech Neurosurg 7: $31-41,2004$

15. Jin D, Qu D, Chen J, Zhang H: One-stage anterior interbody autografting and instrumentation in primary surgical management of thoracolumbar spinal tuberculosis. Eur Spine J 13 : $114-121,2004$

16. Kaya RA, Turkmenoglu ON, Koc ON, Genç HA, Cavuşoğlu $\mathrm{H}$, Ziyal IM, Aydin Y: A perspective for the selection of surgical approaches in patients with upper thoracic and cervicothoracic junction instabilities. Surg Neurol 65: $454-$ 463, 2006

17. Knöller SM, Brethner L: Surgical treatment of the spine at the cervicothoracic junction: an illustrated review of a modified sternotomy approach with the description of tricks and pitfalls. Arch Orthop Trauma Surg 122: 365 - 368, 2002

18. Kreshak JL, Kim DH, Lindsey DP, Kam AC, Panjabi MM, Yerby SA: Posterior stabilization at the cervicothoracic junction a biomechanical study. Spine 27: 2763 -2770, 2002

19. Kurz LT, Herkowitz HH: Modified anterior approach to the cervicothoracic junction. Spine 6 [Suppl]: 542 - 547, 1991

20. Le H, Balabhadra R, Park J, Kim D: Surgical treatment of tumors involving the cervicothoracic junction. Neurosurg Focus 15: e3, 2003

21. Lee SH, Sung JK, Park YM: Single-stage transpedicular decompression and posterior instrumentation in treatment of thoracic and thoracolumbar spinal tuberculosis a retrospective case series. J Spinal Disord Tech 19: 595 - 602, 2006

22. Lenoir T, Hoffmann E, Thevenin-Lemoine C, Lavelle G, Rillardon L, Guigui P: Neurological and functional outcome after unstable cervicothoracic junction injury treated by posterior reduction and synthesis. Spine J 6: 507 - 513, 2006

23. Lifshutz J, Lidar Z, Maiman D: Evolution of the lateral extracavitary approach to the spine. Neurosurg Focus 16: e12, 2004

24. Maiman DJ, Pintar FA, Groff MW: Concepts and mechanisms of biomechanics, in Winn HR (ed): Youman's Neurological Surgery, $4^{\text {th }}$ vol 5. Philadelphia: WB Saunders, 2004: 4181 4201

25. Mazel C, Hoffmann E, Antonietti P, Grunenwald D, Henry M, Williams J: Posterior cervicothoracic instrumentation in spine tumors. Spine 29: 1246 - 1253, 2004

26. Micheli LJ, Hood RW: Anterior exposure of the cervicothoracic spine using a combined cervical and thoracic approach. J Bone Joint Surg [Am] 65: 992 - 997, 1983

27. O'Leary ST, Ganju A, Rauzzino MJ: Costotransversectomy. in Fessler RG and Sekhar L (ed): Atlas of Neurosurgical Techniques: Spine and Peripheral Nerve. New York: Thieme, 2006: $441-447$
28. Pointillart V, Aurouer N, Gangnet N, Vital JM: Anterior approach to the cervicothoracic junction without sternotomy a report of 37 cases. Spine 32: 2875 -2879, 2007

29. Prybis BG, Tortolani PJ, Hu N, Zorn CM, McAfee PC, Cunningham BW: A comparative biomechanical analysis of spinal instability and instrumentation of the cervicothoracic junction an in vitro human cadaveric model. J Spinal Disord Tech 20: 233 - 238, 2007

30. Sapkas G, Papadakis S, Katonis P, Roidis N, Kontakis G: Operative treatment of unstable injuries of the cervicothoracic junction. Eur Spine J 8: 279-283, 1999

31. Sharan AD, Przybylski GJ, Tartaglino L: Approaching the upper thoracic vertebrae without sternotomy or thoracotomy. Spine 25: 910 - 916, 2000

32. Shen FH, Marks I, Shaffrey $\mathrm{C}$ et al: The use of an expandable cage for corpectomy reconstruction of vertebral body tumors through a posterior extracavitary approach: A multicenter consecutive case series of prospectively followed patients. Spine J 8: 329 - 339, 2008

33. Snell BE, Nasr FF, Wolfla CE: Single-stage thoracolumbar vertebrectomy with circumferential reconstruction and arthrodesis: Surgical technique and results in 15 patients. Neurosurgery 58 (Suppl 2): 263 - 268, 2006

34. Steinmetz MP, Miller J, Warbel A, Krishnaney AA, Bingaman W, Benzel EC: Regional instability following cervicothoracic junction surgery. J Neurosurg (Spine) 4: 278 - 284, 2006

35. Street J, Fisher C, Sparkes J, Boyd M, Kwon B, Paquette S, Dvorak M: Single-stage posterolateral vertebrectomy for the management of metastatic disease of the thoracic and lumbar spine: A prospective study of an evolving surgical technique. J Spinal Disord Tech 20: 509 - 520, 2007

36. Wang JC, Boland P, Mitra N, Yamada Y, Lis E, Stubblefield M, Bilsky MH: Single-stage posterolateral transpedicular approach for resection of epidural metastatic spine tumors involving the vertebral body with circumferential reconstruction: results in 140 patients. J Neurosurg (Spine) 3: $287-298,2004$

37. Xiao ZM, Zhan XL, Gong DF, De Li S: Surgical management for upper thoracic spine tumors by a transmanubrium approach and a new space. Eur Spine J 16: 439 - 444, 2007

38. Yoshımoto H, Sato S, Hyakumach T, Yanagibashi Y, Masuda $\mathrm{T}$ : Pyogenic spondylitis in the cervicothoracic junction with high-positioned aortic arch Case report and review of the literature. J Neurosurg (Spine) 3: 242 - 245, 2005

39. Zhang HQ, Guo CF, Xiao XG, Long WR, Deng ZS, Chen J: One-stage surgical management for multilevel tuberculous spondylitis of the upper thoracic region by anterior decompression, strut autografting, posterior instrumentation, and fusion. J Spinal Disord Tech 20: 263 - 267, 2007 